\title{
Male Students and Digital Game: Reason, Motivation and Feeling
}

\author{
Nazirah Mat Sin, Othman Talib, Tengku Putri Norishah, Adura Azlin Ishak, and Roselan Baki
}

\begin{abstract}
The games industry has become one of the most lucrative industries in the world due to the billion dollar sales of digital games. Digital game play is like a culture among majority of students in high schools, especially males who play games every day. This phenomenon has stimulated researchers and academics to further study the various contexts of gaming. This preliminary study has identified the motivating factors of certain games that were able to sustain the interest of five male students in playing those digital games. A basic qualitative research design is adopted as the research method. The findings has reported - five motivating factors which are type of game, content, challenge, control, update and fun that incite students to consistently play the digital games.
\end{abstract}

Index Terms-Qualitative method, male students, digital game, reason, factors.

\section{INTRODUCTION}

Worldwide billion dollars of revenue has been generated from the game industry alone. In 2007, DFC Intelligence had forecasted online game industry would gain USD13.1 billion in year 2012; the figure forecasted was a threefold increase from the revenue gained in year 2006. However, in year 2011 the revenue earned had reached USD 16.54 billion in game content alone [1]. According to another report, the game industry is expected to continuously - generate revenue of USD25.5 billion by 2015 [2]. These figures indicate that the game industry will maintain its growth - in the society, as part of human culture. This situation has occurred due to many reasons. One, technology advancement such as the proliferation of the Internet and gadgets has enabled digital games to be immersed in humans' everyday life.

Besides its billion dollar profits, playing digital games is a popular activity among teenagers. One third of game players consist of adolescence between the ages of 13 to 18 years and the percentage number of game players have been proportionately consistent since 2005 until 2012 [1], [3]. This indicates that gaming is an integral part of the fabric of adolescents' social lives that it is assumed that each child who enters teenage years should be able to know and play games.

Several studies conducted on gaming had reported that

Manuscript received June 4, 2013; revised September 11, 2013.

Nazirah Mat Sin and Tengku Putri Norishah are with the Multimedia University, Cyberjaya 63100, Malaysia (e-mail: nazirah.sin@mmu.edu.my \&tengku.norishah@mmu.edu.my).

Othman Talib and Roselan Baki are with University of Putra Malaysia, Serdang, Malaysia (e-mail: ot@educ.upm.edu.my, ros_baki@putra.upm.edu.my).

Adura Azlin Ishak is with Sekolah Berprestasi Tinggi Sains Alam Shah, 56100 Kuala Lumpur, Malaysia (e-mail: aadurra@yahoo.com). majority of teenagers play digital games; for example in the United States, 93\% out of 1254 students aged 12-14 played games regularly [4]. In Malaysia, more than $90 \%$ of male and female students were found playing digital games inside and outside of the school area [5]. In year 2009, $94 \%$ of game players are aged under 18 [6].

These studies also identified that majority of digital game players consisted of male teenagers: $96 \%$ of Malaysian male students played digital games [7]. A similar finding supported this claim when their research revealed $50 \%$ of male students played games more than 6 hours per week and one third of these boys played games almost every day [8]. Another study reported 54\% male students aged 13 to 17 years old had been playing digital games every day [9].

This phenomenon is inevitable. Based on previous research and reports described earlier in this study, the appeal of digital games, especially among male students, is manifested through the game industry profits, number of game players and time spent playing games. However, these numbers alone could not answer the question has arisen, "What are the reasons that has sustained students' interest to continually play the digital game that they favor most?" Answers gained from this question would help increase understanding of students' motivation in playing digital games. At the same time, it is believed the findings of this study could be adopted and adapted for future research especially in the areas of gaming and learning.

\section{DEFINING GAME}

There are varying definitions of game with no one standard definition that could be found [10]-[12]. Although there aren't any standard definitions that can be used to describe game, in this study game is defined as an interaction of one or more players with multimedia components. The interaction is based on specific rules which a player has to follow in order to achieve the goals of a game. The terms digital game and game terms will be used interchangeably in this research article.

\section{THEORETICAL FrAMEWORK}

Motivation consists of external and intrinsic motivation. External motivation refers to doing an action for the purpose of gaining a reward in material form. Whereas, intrinsic motivation mainly refers to an action performed for the sake of the act alone, which is considered rewarding in itself [13].

Intrinsic motivation occurred when “... people engage in it for its own sake, rather than in order to receive some external rewards or to avoid some external punishments" [14]. In the 
digital game play context, intrinsic motivation can be defined as the drive to play digital game that subsequently produces the emotion of fulfillment. In this study, intrinsic motivation is used as the underlying theoretical framework; the rationale for choosing intrinsic motivation is due to its role in-spurring game players to enjoy playing digital games [15]. In this study the word intrinsically motivating, fun and interest are used interchangeably.

\section{GOAL OF THE CURRENT STUDY}

The goal of this qualitative study is to understand in detail the factors that motivated five male high-school students to continually play their preferred digital game consequently, the study would give an insight-on students' motivation when playing digital games.

This study addresses the following research questions:

- What are the reasons that have influenced students to favor certain games?

- What reasons motivated students to continually play the digital game they favored most?

- How do students' feel when they are playing the digital game that they favored most?

\section{DESIGN OF THE STUdY}

\section{A. Qualitative Research}

Qualitative research is conducted to understand and explore an environment or situation. In conducting a qualitative research, data are collected through observation, interview and documentation [16]. For this research, qualitative research is applied as the purpose of the study was to understand students' perspective towards games. More specifically, a basic qualitative study had been used as the research method: Basic qualitative method is used when the qualitative methodology selected for a study does not fit into other methodologies in the qualitative approach [17].

\section{B. Participants}

Participants of the study were selected using purposive sampling method as purposive sampling approach is the most appropriate sampling method when using qualitative approach [16]. Furthermore, purposive sampling has enabled the researcher to gain a detailed understanding of students' real motives when playing digital games. In this study, the participants consisted of 5 male students from a government boarding school in Kuala Lumpur. The students selected correspond to the criteria of being active game players: These students have claimed that they play digital games, on average, at least 3 hours a day during school holidays and 1 to 2 hours a day during school terms. Since these students were studying in a boarding school, they were chosen based on the time spent playing digital game during school holidays. Coming from one setting, all these students came from the same boarding school. Choosing a single setting for qualitative studies is acceptable as the purpose of qualitative study is not to establish generalized information but to report rich information provided by participants [16]. Furthermore, due to limited time given for the research project, the number of participants as well as the single setting is deemed appropriate.

\section{Instrumentation}

A semi-structured interview was used in the study the instrument to collect data for this study: Consisting of open ended questions,--the interview would encourage participants to voice their experiences and opinions without any influence from the researcher of the study [16].

TABLE I: PARTICIPANTS OF THE STUDY

\begin{tabular}{|c|c|c|c|c|}
\hline $\begin{array}{l}\text { Partici } \\
\text {-pants }\end{array}$ & Game & $\begin{array}{l}\text { Type of } \\
\text { Game }\end{array}$ & $\begin{array}{l}\text { Hours } \\
\text { spent } \\
\text { (during } \\
\text { School } \\
\text { day) }\end{array}$ & $\begin{array}{l}\text { Hours spent } \\
\text { (during } \\
\text { holiday) }\end{array}$ \\
\hline Is & Ninja Sage & $\begin{array}{l}\text { Role Play } \\
\text { Game }\end{array}$ & 2 hours & 3 hours \\
\hline Naqi & War Craft 3 & $\begin{array}{l}\text { Role Play } \\
\text { Game }\end{array}$ & - & 5-7 hours \\
\hline Daniel & $\begin{array}{l}\text { Counter } \\
\text { Strike }\end{array}$ & $\begin{array}{l}\text { Role Play } \\
\text { Game }\end{array}$ & $\begin{array}{l}1-2 \\
\text { hours }\end{array}$ & - \\
\hline Aqil & $\begin{array}{l}\text { PES (Pro } \\
\text { Evolution } \\
\text { Soccer) }\end{array}$ & $\begin{array}{l}\text { Sports } \\
\text { Game }\end{array}$ & 1 hour & $>5$ hours \\
\hline Amirul & $\begin{array}{l}\text { Grand } \\
\text { Tourist } \\
\text { More } 4\end{array}$ & Car Race & 2 hours & 4-5 hours \\
\hline
\end{tabular}

The interviews were conducted one on one with all 5 participants of the study. Although this approach has taken more time compared to other types of interview, this approach enabled the researcher to study in-depth the motives of each participant when playing a digital game. Furthermore, the one-one-one interview is the most common approach employed in educational research [16].

\section{Procedure}

"An interview protocol is a form designed by the researcher that contains instructions for the process of interview, the questions to be asked, and some space to write notes of the responses from interviewees" [16]. In this study, an interview protocol had been prepared to guide the researcher before and during the data collection process.

Prior to the interview, each participant was given a written consent form to fill up to indicate their agreement to participate in the study. Moreover the researcher had explained the purpose of the research to participant during which every participant were informed that their participation is voluntary. Each participant then was given an ample time to read and sign the consent form.

During the interview sessions, data was collected using a digital audio recorder application in a smart phone. Concurrently, notes were also taken by the researcher as a backup [16].The questions asked to the participants were based on a set of predetermined questions that had been used as a guideline for the researcher. Additionally, probes were used to clarify responses that were considered ambiguous and insufficient [16]. The interview sessions were conducted using both the English and Malay Languages; the Malay language had been included as a medium of communication 
for the study as most students were comfortable to express their opinions and feelings using their native language. On top of that, it is believed the participants would give more comprehension feedback when expressing their ideas in the Malay Language.

The interview sessions ended with the researcher thanking each participant and assuring them that she will ensure the discretion of their responses.

\section{E. Data Analysis}

Basic thematic analysis approach had been used to analyze the collected data. The collected data were transcribed, with descriptions of the data based on the research questions. The Data were then categorized into several themes. At the final stage, the emerged themes were categorized according to three main themes.

As mentioned in the procedure section, most data had been collected in the Malay Language, which were then translated into English during the transcription and followed by data analysis. This strategy has been employed by many students. Maryam further explained that a bilingual person should be appointed to check the translation reliability; reliability is accessed based on the level of proximity between meanings of the original data and the translated version [17]. However, in this study, the data translated had not been accessed by a third person; therefore, this issue is considered as a limitation of the study.

\section{FINDINGS AND DISCUSSIONS}

The following results are organized in terms of the research questions presented in this paper:

\section{A. What Are the Reasons That Have Influenced Students to Favor Certain Games?}

The first research question focused on the reasons why students favor certain games as their choice to play. Type of game and game content were the two salient themes that emerged during the analysis procedure.

\section{B. Type of Game}

The first recurring theme identified was type of game. All students described that the type of digital game attracted them to favour certain digital games for playing. Student Amirul and Student Aqli, for example, preferred car race game and sports game. Whereas the remaining students favored certain digital games because the digital games is a role play game (RPG) type. The following interview excerpts exemplify this:

\section{It is about cars.}

An excerpt from interview with Student Amirul

This game is about football. It captured my interest.

An excerpt from interview with Student Aqil

At first we have to find the enemies...then we have to escape from our enemies. Then we must seek ways to attack our own enemies. Satisfaction is gained from the strategy itself.

An excerpt from interview with Student Daniel

The game concept is ninja. Similar to Nauto..in this game I like the Naruto anime. If I watch the game..yeaa...I like Naruto

An excerpt from interview with Student Is

Because I like playing strategy game and RPG game, this war craft game have both elements of RPG and strategy.

An excerpt from interview with Student Naqi

\section{Game Content}

The next theme emerged from the interview process was game content. The students justified that they like to play the digital games because of the game content. These students were playing the digital games intentionally to their increase knowledge and skills in various areas that interest them most; it is not solely for entertainment's sake. The following interview excerpts exemplify this:

It is about cars. Usually the game provides about real information of cars. Other car games would simply state information about the cars without stating the real specifications of a car. For example a Ferrari. Much information can be attained about Ferrari through this game.

An excerpt from interview with Student Amirul

I like football sport. This game is about football. It captured my interest. Sometimes I can learn skills of playing football in the game itself.

An excerpt from interview with Student Aqil

Two main reasons that influence students to play the digital game they favored most had been identified in this research. One of the main reasons is - the type of digital games the students played. Various types of games can be found in the market including sports, racing and role play games [10].This study has discovered that the type of games such as role play game, car race game or sports game has influenced participants to favor certain games. The finding found in this study is similar to a study that had been reported by male students favored car race, sports games and role play game [18]. Similar findings had been also found from a study conducted by; the study reported that the male participants favored playing role play games [19].

Game content has been identified as the second reason that influence students to play the digital games t they favored most. Findings from the data discovered that students played digital games to increase their knowledge and skills, such as playing a car racing game to increase knowledge about a specific car. Another example mentioned by a participant, is a football digital game. As a football player for his school, he favored the football digital game because he wanted to improve his football skills. Thus, this indicates that not all students play digital games solely for entertainment purpose. These students obviously leverage on their games for learning purposes especially when it relates to information that attracts their interest. Subjects such as cars and sports usually attract male students. As most car and sport games are available in the market, it is not surprising these students opt to learn about the topic they like by playing a digital game rather than seek information from reading books or surfing 
the internet. Findings of this study is consistent with a study that discovered that one of the motives students were playing digital games was to acquire new knowledge [4]: Although the study did not mention specifically the type of knowledge learned by respondents-in the study, the findings discovered that students had been utilizing digital games for learning. Besides that, digital games could be used to acquire new knowledge and skills [20]. In conclusion, the findings of this study had found that students were aware of the potential of digital games as a learning tool; moreover participants of the study had been utilizing digital games to acquire new skills and to increase their cognitive ability.

\section{What Reasons Motivated Students to Continually Play the Digital Game They Favored Most?}

When Asked about the Factors that Motivated Them to Continually Play a Digital Game, the Opinions of Students Uncovered 3 Main Themes Which Are: Challenge, Control and Constant Updates.

\section{E. Challenge}

The most frequent theme that surfaced from the second research question was sense of challenge. Many students mentioned that one of the reasons that motivated them to continually play the digital game they favored most were the challenges that had been embedded in the digital games. The following interview excerpts exemplify this reason:

At first, this game starts at level 1. As the levels increased, so do the difficulties. That is why I want to win

An excerpt from interview with Student Amirul

Ok...this game actually has levels. If we play, it has challenges from level one, two, level three up to level 20. We will get one title.

An excerpt from interview with Student Is

When you play the game and reach certain level, you will get a new ability...So I will keep playing and playing until my character reach the highest level

An excerpt from interview with Student Naqi

For example, a sniper needs to shoot somebody from a long distance with accuracy and for example, if two doors open slightly ajar and if an enemy walks through we have to straight way shoot. That is one of the skills.

An excerpt from interview with Student Daniel

The game is challenging. I felt challenged when playing the game. We can choose the difficulties, and level of difficulties. The most difficult level would be very challenging.

An excerpt from interview with Student Aqil

\section{F. Control}

The second most frequent theme that emerged from the second research question is control. Many students mentioned that one of the reasons that motivated them to continually play the digital game they favored most were their power to control the digital games. All the interactions and feedbacks from the games had been effected by the decisions and actions made by the digital game players. The following interview excerpts exemplify this:

Because when the level increases its gives us power An excerpt from interview with Student Is

With the new ability you can kill other players even more. An excerpt from interview with Student Naqi

For example, a sniper must have accuracy to shoot somebody from a long distance and for example, if there were two doors open slightly ajar and that is a skill. If enemy walks through we have to straight way shoot.

An excerpt from interview with Student Daniel

\section{G. Constant Update}

Constant update is another reason that has motivated these students to continually play the digital game they favored most. The following interview excerpts exemplify this:

The game is updated annually. It has 2011, and 2013 batches. Each year, the game will be updated in terms of players, quality of the game play and video. Sometime, I am attracted to try these new updates.

An excerpt from interview with Student Aqil

Such as during Christmas, the game has updates. It means, for example, if it is a Halloween day the game will make us fight the Halloween to get the Halloween power. The game always have updates.

An excerpt from interview with Student Is

Digital game players consistenly play the digital games due to four main criteria that are embedded in most digital games: Challenge, curiosity, control and fantasy [14]. These four main elements are believed to be able create an enjoyable emotion when players play digital games.

In this study, one of the primary reasons that motivated students to contunually play the digital games they favored most was the challenges that had been embedded in the game play. This finding is supported by Malone and Lepper's research that claimed when challenges are implanted in games, it motivate students to play game. Much research conducted about games reported that challenge is one of the most important elements that attract students to play games [21]-[23].

Challenge refers to game difficulties that are not too difficult and yet not too easy. The sufficient level of challenges in a game motivates students to continually play a game [24]. In this study, the difficulty levels of a game from the most minimal level until the maximum level had motivated students to continually play the games. The level of difficulties had stimulated the students' desire to overcome obstacles to reach the game's highest level, to earn a reward and lastly, to win the game [14].

The second reason that motivates students to continually play digital games that they favored most is control. Game gives powerful sense of control to the players [25]. One of the elements that provide game players sense of control is a cause-and-effect situation. An outcome is the result of 
responses by students during game play. However, the outcome is uncertain until an action has taken place during a game play [14]. For example 'a sniper must be accurate when shooting somebody from a long distance; for example, if two doors opened slightly ajar, it is a skill to straight away shoot if an enemy walked through one of the doors.' [Student Daniel]: In this situation, the outcome of an enemy being shot is not confirmed until the player shoots the enemy during the game play. Thus, this situation creates an element of control and suspense for game players.

The last reason that motivated students to play digital games is update; update refers to improvements made on digital games like enhancement of game content, level of difficulties, interface, reward and etc. Interestingly, previous research could not be found by the researcher on this matter although update has been found in this study as one of the motives that could sustain students' motivation in playing games. Researchers of previous studies included entertainment, challenge, communication and competition as the reasons for students playing games [20]. Thus, it is proposed that update should be included as one of the reasons that motivated students to continually play digital games, and further study on update should be conducted.

\section{H. How do Students Feel When They are Playing the Digital Game That They Favored Most?}

The third research question focused on the feelings students felt while they were playing the digital games they favored most. One main theme emerged during the analysis procedure which is feeling fun. The following interview excerpts exemplify this reason:

\section{Fun}

\section{Felt happy when I was able to kill our enemies.}

An excerpt from interview with Student Daniel

The feeling is fun because the game required high level of patience. We must know how to use because we will have more power. We can kill whoever we wanted. We can lose the power and we will be defeated. If we lose we can still enter the game using other power. That's the reason I like the game.

\section{An excerpt from interview with Student Is}

Most students expressed enjoyment when asked about their feeling during game play. The enjoyment or fun feeling emerged when these players have experienced the motivation factors that were explained earlier: The feeling of fun is expressed when the players manage to achieve the goal game such as 'Felt happy when our enemies were killed.' [Student Daniel] The feeling of fun can also be triggered when students are able to control the game as expressed by one of the participants 'The feeling is fun because the game required high level of patience. We must know how to use our patience because we will have more power. We can kill whom we want. But we can lose the power and we will be defeated. If we lose we can still enter the game using other forms of power' [Student Is]. Findings found in this study are similar to a study who reported enjoyment feeling was an important element in game creation: The enjoyment could be achieved through challenges, goals and feedback [20].

\section{CONCLUSION}

In summary, the study had found that students are attracted to games based on the type and content of games that have relevance to them. The study also found that the elements of challenge, control and update in games have the potential to sustain students' motivation when playing games. Finally, the anticipated outcome during game play would be the feeling of fun.

This small scale study is a preliminary study conducted to understand students' perspectives and feelings towards games that they favored most. It is realized that many limitations including validity and reliability issues were not taken into consideration. Thus, this had disabled transferability of the study. Further study will be conducted using heterogeneous participants and more in depth interview analysis.

\section{REFERENCES}

[1] Entertainment Software Association. [Online]. Available: http://www.theesa.com/facts/index.asp

[2] PC games market reports record \$18.6 billion for 2011. [Online]. Available: http://www.dmwmedia.com

[3] Entertainment Software Association. [Online]. Available: http://www.theesa.com/newsroom/soi_2005.asp

[4] C. K. Olson, L.A. Kutner, D. E. Warner, J. B. Almerigi, B. Lee, and A M. Nicholi. (2007). Factors Correlated with Violent Video Game Use by Adolescent Boys and Girls. Journal of Adolescent Health. [Online]. 41. pp. 77-83. Available:

http://www.grandtheftchildhood.com/GTC/Research_Papers_files/Ols on_JAH\%207-07.pdf

[5] A. L. Rubijesmin. (2007). Understanding Malaysian students as gamers: Experience. ACM DIMEA 2007. [Online]. pp. 137-141. Available: http://dl.acm.org/citation.cfm?id=1306843

A. C. Clark and J. Ernst. (2009). Gaming Research for Technology Education. Journal of Science, Technology, Engineering and Mathematics (STEM) Education. [Online]. 10(1\&2). pp. 25-30. Available:

http://jstem.org/ojs/index.php?journal=JSTEM\&page=article\&op=vie wFile\&path\%5B\%5D=1449\&path\%5B $\% 5 \mathrm{D}=1251$

[6] A. L. Rubijesmin. (2007). Understanding Malaysian students as gamers: Experience. ACM DIMEA 2007. [Online]. pp. 137-141. Available: http://dl.acm.org/citation.cfm?id=1306843

[7] C. K. Olson, L.A. Kutner, D. E. Warner, J. B. Almerigi, B. Lee, A. M. Nicholi. (2007). Factors Correlated with Violent Video Game Use by Adolescent Boys and Girls. Journal of Adolescent Health. [Online]. 41. pp. 77-83. Available:

http://www.grandtheftchildhood.com/GTC/Research_Papers_files/Ols on_JAH\%207-07.pdf

[8] Profile of Canadian Gamers. [Online]. Available: http://www.theesa.ca/

[9] R.C. Clark and R. E. Mayer, E-Learning and the Science of Instruction, San Fransisco: Pfeiffer, 2011, pp. 461.

[10] L. P. Rieber, Multimedia learning in games, simulations, and microworlds, New York, NY: Cambridge University Press, 2005.

[11] M. Prensky, "Digital Natives, Digital Immigrants," In On the Horizon, October 2001, Lincoln: NCB University Press, vol. 9, no. 5.

[12] J. Bruner, Toward a Theory of Instruction, Cambridge: Harvard University Press, 1966.

[13] T. W. Malone and M. R. Lepper, "Making learning fun. A taxonomy of intrinsic motivations for learning," in R. E. Snow and M. J. Farr (Eds.), Aptitude, Learning, and Instruction, Cognitive and Affective Process Analyses, Hillsdale, NJ: Lawrence Erlbaum, 1987, vol. 3, pp. 223-253.

[14] T. Hainey, T. Connolly, M. Stansfield, and E. Boyle. (2011). The differences in motivations of online game players and offline game players:A combined analysis of three studies at higher education level. Computers \& Education. [Online]. pp. 2197-2211. Available: http://www.sciencedirect.com/science/article/pii/S0360131511001308 
[15] J. W. Creswell, Qualitative inquiry and research design: Choosing among five traditions (3rd ed.), Thousand Oaks, CA: Sage, 2012.

[16] S. B. Merriam, Qualitative research: A guide to design and implementation, San Francisco: Jossey-Bass, 2009.

[17] T. Karakus, H. Sancar, and K. Cagiltay, "An Eye Tracking Study: The Effects of Individual Differences on Navigation Patterns and Recall Performance on Hypertext Environments," presented at the World Conference on Educational Multimedia, Hypermedia and Telecommunications (EDMEDIA), 2008.

[18] Y. L. Eow and R. Baki. (2008). An Exploratory Study on the Reasons and Preferences of Six Malaysian Students on the Video Games Played Journal of Environmental \& Science Education. [Online]. pp. 19-25. Available: http://www.ijese.com/V3N1.htm

[19] E. A. Boyle, T. M. Connolly, H. Thomas, and J. M. Boyle, (2012). Engagement in digital entertainment games: A systematic review. Computers in Human Behavior. [Online]. 28(3), pp. 771-780. Available:

http://www.sciencedirect.com/science/article/pii/S0747563211002640

[20] K. Lucas and J. Sherry. (2004). Sex differences in video game play: a communication-based explanation. Communication Research. [Online]. pp. 499-523. Available: http://icagames.comm.msu.edu/cr.pdf

[21] T. Connolly, E. Boyle, and T. Hainey, "A survey of students' motivations for playing computer games: a comparative analysis," in Proc. the 1st European conference on games-based learning, 2007.

[22] T. Hainey, T. Connolly, M. Stansfield, and E. Boyle. (2011). The differences in motivations of online game players and offline game players:A combined analysis of three studies at higher education level. Computers \& Education. [Online]. pp. 2197-2211. Available: http://www.sciencedirect.com/science/article/pii/S0360131511001308

[23] K. A. Wilson et al., (2009). Relationships Between Game Attributes and Learning Outcomes:Review and Research Proposal. Simulation \& Gaming. [Online]. pp. 217-266. Available: http://sag.sagepub.com/content/40/2/217.abstract

[24] H. Moon and Y. Baek, "Exploring Variables affecting Player's Intrinsic Motivation in Educational Games Education," in Proc. the 17th International Conference on Computers in, 2009, pp. 718-723.

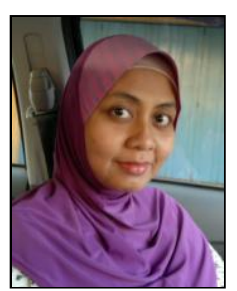

Nazirah Mat Sin obtained her first degree in bachelor of multimedia (honours) (digital media) from Multimedia University, Malaysia in year 2001. She received her Master of Science (Creative Multimedia) from the same university in year 2009. In 2010 she obtained her second masters in Master of Instructional Technology from University of Malaya, Malaysia. She is currently pursuing her $\mathrm{PhD}$ in Faculty of Educational Studies in University of Putra Malaysia. Her research interests include instructional and educational technology, multimedia, knowledge management. She is currently a lecturer in Faculty of Creative Multimedia, Multimedia University. She is a program coordinator in Master of Multimedia (e-Learning Technologies).

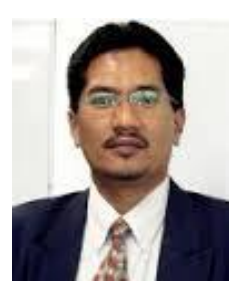

Othman Talib completed his secondary and post-secondary education at the King George V Secondary School, Seremban and the Matriculation Centre, University Kebangsaan Malaysia (UKM). He completed his first degree in Chemistry from UKM in 1986. He then appointed as a Chemist (temporary basis). A year later, he was appointed as a Chemistry teacher at the Matriculation Centre, University Putra Malaysia (UPM). He completed his Master in Pedagogy from UPM in 1999 and then in February 2000, was appointed as a lecturer with the Faculty of Educational Studies, UPM. He pursued his study at the University of Adelaide, Australia and obtained the Doctor of Education degree in 2007.

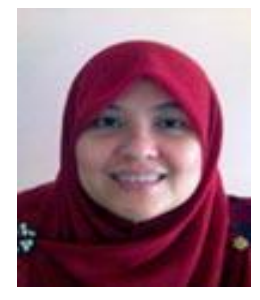

Tengku Putri Norishah obtained her first degree in bachelor of arts (hons), English Language Studies from Indiana State University, Indiana in 1994. She completed her Master in Education from Indiana University, Indiana in 1996. She is currently in the process of completing her $\mathrm{PhD}$ in University of National, Malaysia. She is also a deputy dean in Faculty of Creative Multimedia, Multimedia University.

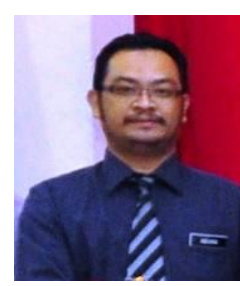

Adura Azlin Ishak obtained his degree in bachelor of science in education and computer from University of Technology Malaysia in year 2000. He is currently an Excellent Teacher in Sekolah Menengah Sains Alam Shah, Kuala Lumpur, Malaysia. His area of experts are in Chemistry and Information Communication

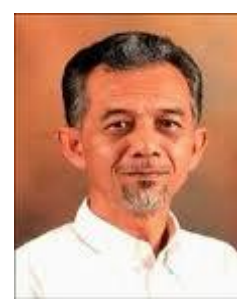

Roselan Baki completed his high school at Sekolah Dato'Abdul Razak, Tanjung Malim, Perak dan Sekolah Dato'Abdul Razak, Seremban, Negeri Sembilan. He holds the doctoral degree from Universiti Kebangsaan Malaysia. He was appointed as a senior lecturer with Universiti Putra Malaysia in 2004. after serving 10 years as high school teacher and 14 years as alecturer at Institut Pendidikan Bahasa Melayu Malaysia. 